\title{
A PHOTOGRAMMETRIC WORKFLOW FOR RAPID SITE DOCUMENTATION AT STOBI, REPUBLIC OF NORTH MACEDONIA
}

\author{
K. Jones ${ }^{1 *}$, G. Bevan ${ }^{1}$ \\ ${ }^{1}$ Queen's University, Department of Geography \& Planning, Kingston, Canada - (k.jones, bevan)@ queensu.ca
}

KEY WORDS: Cultural Heritage, Photogrammetry, Documentation, 3D Modeling, Architecture, Republic of North Macedonia

\begin{abstract}
:
The so-called "Theodosian Palace" is one of the most significant Late Antique structures at the site of Stobi, in the Republic of North Macedonia. Popularly thought to be a stopping-place of Theodosius I on his way through the province of Macedonia Secunda according to the evidence of the Codex Theodosianus, the structure is in dire need of conservation with many of the stone and mortar walls threatening to collapse onto the mosaic floors below. Any conservation effort in the Republic of North Macedonia must produce rigorous documentation before any physical work can take place. The most important and time consuming component of the project preparation are section and elevation drawings documenting each of the walls stone-by-stone, with elevations and scales indicated in a format prescribed by the state. These drawings are usually done manually on graph paper in the field, with the assistance of time-honoured manual tools -- the plum-bob and tape-measure --, but this method is enormously time consuming and has considerable of room for error. The present project, begun in 2016 and the subject of this paper, endeavoured to show that new, photogrammetric methods could not only improve the accuracy of these drawings, but also the speed with which they are made. Our results demonstrate an increase in accuracy by an order magnitude, from $3 \mathrm{~cm}$ to $3 \mathrm{~mm}$, and an improvement in the time to deliver the final product from an estimated 8 months to 2 months.
\end{abstract}

\section{INTRODUCTION}

The archaeological site of Stobi in the modern Republic of North Macedonia, inhabited from the Hellenistic to Late Antique periods, is an internationally important ancient site (Fig. 1). Many teams have excavated and conducted research at Stobi since its discovery by German scholars in the late 19th century (von Hahn, 1861; Heuzy, 1873). Currently it is under the supervision of a government institution, National Institution Stobi (henceforth NI Stobi), which is responsible for all of the excavation, conservation, touristic, and maintenance activities undertaken at the site. The so-called "Theodosian Palace" is the most opulent residential building discovered at Stobi to date with its elaborate decoration and a plethora of mosaic floors (Fig. 2). The building itself has seen some conservation/restoration work since its discovery in 1927, but much of it remains in dire need of conservation to prevent further stone-decay and mortar deterioration so that unstable walls of 1 to 3 metres do not collapse onto the mosaic floors below. Academic study of the structure is difficult as no surviving records of the earliest excavations of the Theodosian Palace in the late 1920s survive today beyond short preliminary excavation reports, and several rudimentary ground plans (view of the tops of the walls and rooms). With no detailed documentation on hand, drawings are urgently needed to proceed with the full conservation of the building.

It is required by law in the Republic of North Macedonia to provide technical documentation of all active excavations and structures being prepared for conservation. The Republic of North Macedonia has rigorous regulations for the preparation of a project proposal for conservation of any cultural heritage material. In the case of architectural conservation, such as for the Theodosian Palace, the project must consist of a complete inventory of stone-by-stone, to-scale line drawings of the facades of each wall in need of conservation, a stone-by-stone ground plan of the building indicating which areas are to be conserved, detailed narratives of each wall and room that describe the present state and any prior conservation efforts with photographic support, mortar samples, as well as a description of the planned conservation methods that would be undertaken. Prior to the development of photogrammetry and the widespread availability of high-power computers and digital cameras, technical drawings on archaeological sites were done by hand with rulers, compasses, and plumb-bobs. As is common at many archaeological sites, Stobi traditionally used manual drawing for all of its documentation. Excavation areas, building plans, and sections would all be drawn by hand on graph paper using references to excavation grid squares in the form of iron nails. There are many sources of error in this process, as experience has shown us, and we aim to find an alternative method that is both faster and more accurate than hand drawing. Scale, typically 1:50, becomes the absolute limiting factor for the accuracy of hand drawings without taking into account any sources of error due to mismeasurement with the rulers and plumb-bobs. Additional inaccuracies are introduced during the digitization process which involves scanning the drawings into a computer, and then tracing them using vector graphics programs such as AutoCAD or CorelDraw, and finally manually fitting them into the ground plan of the site.

This project aims to create the missing inventory of drawings of the unconserved walls of the building, both ground plans and sections. Our proposal would eliminate many of the sources of error involved in manual drawing and will improve the speed of documentation. We propose a rigorous stereo-plotting workflow using digital terrain models (DTMs) as a method for

* Corresponding author 
producing very high accuracy archaeological vector drawings. Digital photogrammetry has rapidly become a standard documentation technique in archaeological excavation over the past decade. This project proposes a time and cost-effective method for the process of photogrammetric recording for the purpose of generating technical drawings of archaeological features. With the creation of a dense control network on the site, accurate to $3 \mathrm{~mm}$, the photogrammetric models can be georeferenced within the site and integrated with past and future data in order to analyse spatial relationships. The control network becomes the limiting factor for the accuracy of the models, not the photogrammetry itself, which is typically capable of achieving millimetric, even sub-millimetric, accuracy in close-range applications. With the use of commercial photography equipment and an engineering-grade total station, we are able to produce a 3D model of the entire building to an accuracy of $3 \mathrm{~mm}$. The 3D models are subsequently used as the basis for stereo-plotting the features of the top and façade of each wall stone-by-stone to create the ground plan and section drawings required for conservation. With the advent of inexpensive stereo-display hardware, we show that drawing directly onto oriented DTMs in the coordinate system of the site at a scale of 1:1 using 3D glasses offers a complete digital alternative to manual drawing on site. The scale of $1: 1$ is maintained throughout the entire drawing process and scale is only applied when the drawings are plotted for printing. These drawings are used as a record of the state of the building pre-conservation, as well as by the architect for planning and guiding the conservation process. The initial drawings will be annotated to show where stones may be added to stabilize and level the walls as well as the areas where new mortar needs to be applied.

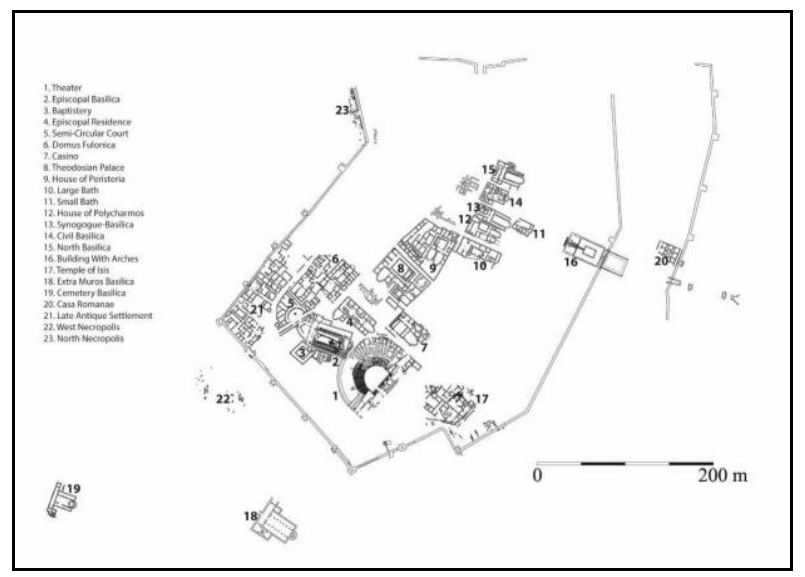

Figure 1. Ground Plan of Stobi in Current Excavation State

\section{FIELD SITE}

The ancient city of Stobi was the capital of the Roman province of Macedonia Secunda (Snively, 2010). The site is located at the strategic confluence of the ancient Axios and Erigon Rivers (the modern Vardar and Crna, respectively) and was a common crossing point between the East and West halves of the Roman Empire. The Axios River, which provided access to Thessaloniki and the Aegean Sea, was a major trading route within the Empire. The site has a rich history during its inhabitation from the $3^{\text {rd }}$ century $\mathrm{BC}$ to the late 6th century $\mathrm{AD}$, after which it was almost completely abandoned (Wiseman, 2007).
Stobi has a history of excavation dating back to the late 19th century by several international teams. There are few surviving records of excavations undertaken prior to the joint AmericanYugoslav project in the 1970s. While a number of articles were published on the site by scholars in the early and middle 20th century, there are no detailed records of the excavation process with complete lists of finds and technical drawings. It was estimated in 2003 that between 300-350 scholarly articles have been published on Stobi to date including excavation reports, reviews, guides, historical analyses, studies, and bibliographies, but none constitute true final reports with complete presentations of the underlying archaeological data (Mikulcic, 1981). The majority of the buildings uncovered to date belong to the Late Antique period during the prime of the city before its abandonment in the 6th century AD. The Theatre, Building with Arches, Temple of Isis, Casa Romana, and Synagogue belong to the Roman period from the 1st to 3rd centuries AD while the rest of the buildings excavated to date belong to the Late Antique period from the 4th to 6th centuries AD. From the time of its destruction, until its re-discovery, the city was essentially undisturbed unlike many of its historic counterparts that have modern cities and towns built upon their ruins such as ancient Scupi in modern Skopje.

The Theodosian Palace, first discovered in 1927 by a Serbian team from the National Museum in Belgrade and excavated for three seasons until 1929 (Petkovic, 1928), is the most impressive of the five residential buildings excavated thus far at Stobi. After the first season, not enough of the building was uncovered for its full significance to be realized, and it was, at the time, believed by the excavators to be a bath, or possibly a sanctuary dedicated to the mysteries of Bacchus (Hemens, 1986). By the end of the season in 1929, the majority of the building was excavated to the original floor level (Petkovic, 1929). Coins discovered at the floor level that are attributed to the reigns of Justin II (565-578 AD) and Maurice (582-602 $\mathrm{AD})$ provided the terminus post quem for the abandonment and destruction of the building, a date consistent with the abandonment of the site as a whole (Hemens, 1986).

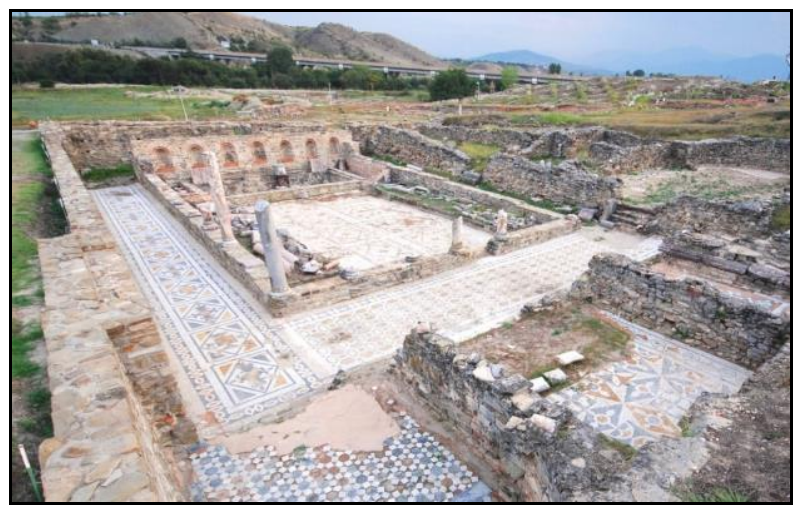

Figure 2. The Theodosian Palace

A number of conservation projects have focused on the Theodosian Palace, but few are well documented. In the 1950s and 1960s, conservation of a portion of the palace was undertaken by the Conservation Institute of Macedonia. They performed minor preventative conservation on the most deteriorated areas of the walls to prevent them from collapsing, but no very major conservation was undertaken. From the time of its discovery until the $21 \mathrm{st}$ century, it is clear that conservation efforts were undertaken several times as up to three different types of mortar can be found in the walls, but 
due to the lack of records and documentation available, the specifics of any of these interventions are unknown. It is also during this earlier period that the concrete seal on the top of the majority of the currently un-conserved walls is believed to have been added. Capping the tops of walls was done to protect the loose material and was intended to prevent further deterioration. Further conservation was performed in 2005 by the National Conservation Centre in Skopje. The conservation done during this time focused on the peristyle area, the long Northeast corridor, and the Southern section of the building. During this conservation project, the damaged walls were stabilized with mortar fill and, in some cases, minor restoration was performed in the form of additional stones added to build up the walls to a level line. The mortar that was used to reinforce the walls was not of the same material composition as the original mortar and thus is of a different colour and does not appear authentic in comparison with the original building materials. All of the conservation undertaken at Stobi uses existing stones uncovered during excavations throughout the site to maintain some measure of authenticity.

\section{METHODS}

\subsection{Project Specifics \& Workflow}

The process for this project was developed and optimized over the course of two field seasons at the site of Stobi during the summers of 2016 and 2017 and is largely consistent with the CIPA "3x3 Rules" (Waldhäusl \& Ogleby, 1994). Photogrammetry provides us with a number of possible outputs that can be used as-is or inputted into down-stream programs for further analysis and annotation. The workflow below outlines the process of obtaining the interior orientation, exterior orientation, and absolute orientation of the image sets required for generating the final 3D models.

The workflow for this project is as follows:

I. Develop a high accuracy control network

II. Calibrate the camera

III. Photography in the field (nadir and terrestrial)

IV. Photogrammetry processing in ADAM Technology's CalibCam and Agisoft Photoscan

V. Stereo-plotting stone-by-stone in Adam Technology's 3DM Analyst

VI. Finalizing the drawings in AutoCAD Map 3D

VII. Combine final scaled drawings with supplementary material

VIII. Completion of conservation project as per standards set by the North Macedonian government

\subsection{Developing the Control Network}

The georeferencing ability of our high accuracy models begins with the creation of a very accurate dense control network for the entire site. A motorized Leica TCRM1201+ Total Station with a 1 arc-second angular accuracy was used for the creation of the control network and all subsequent surveying on the site. Control points were placed around the perimeter of the site as well as throughout its interior to ensure that a minimum of 3-4 ground control points could be sighted from each position on the traverse, which covers a total area of approximately 20 hectares. The control points were distributed around the site on stable structures, such as the fortification walls and staircases, in order to avoid the possibility of movement over the years and are marked with paint in the shape of a red dot surrounded by a circle for easy identification. The distribution of control points was designed such that at least four points could be seen from anywhere on the site. In most cases, however, five to six points are visible so that a high-level of redundancy is possible during a "resection" or "free-station" set-up for excavation work.

Each control point was measured from each adjacent control point through Leica's 'Sets of Angles' program. 'Sets of Angles' was used to measure multiple sets of directions and distances to predefined points (Leica Geosystems, 2007). This application was used instead of the conventional "Survey" application as it permitted automated, repeated measurements of individual points. Each measurement was also taken in two faces to increase accuracy and cancel out any line-of-sight error, tilting-axis error, and height-index error in the instrument. For each position, a series of 6-9 sets were taken of each visible control point to increase accuracy using the Central Limit Theorem. According to the theorem, the standard error of the mean decreases by the standard deviation divided by square root of the number of observations. Thus, in order to triple the accuracy from a single measurement, 9 sets are required, and to quadruple it, 16 sets would be required. We used MicroSurvey Star*Net V8 (MicroSurvey, 2014), to apply a Least Squares adjustment to the measurements to distribute the error across the network according to variances in the instrument and instrument set-up that were entered in advance of the adjustment (Fig. 3). Star*Net is recognized as producing industry-leading, detailed statistical reports on the accuracy of each ground control point after the adjustment and is widely used in applications such as deformation monitoring. For the control network at Stobi, three points were kept fixed (i.e., they were kept constant and their values would not be changed by the adjustment) and the remaining 12 points were adjusted by the software using Least Squares. For our survey, the average error ellipses are on average $3 \mathrm{~mm}$ which provides the limiting absolute accuracy for all further photogrammetry work.

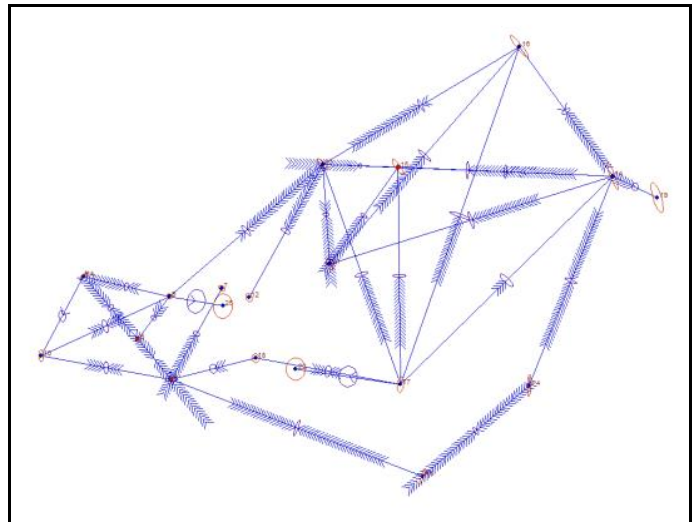

Figure 3. Star*Net Least Squares Adjustment Result

\subsection{Data Collection}

Prior to photography in the field, the camera and lens to be used are pre-calibrated in order to have an initial solution for the interior orientation parameters of the camera. Calibration sequences are performed on highly textured scenes with large differences in depth. In the case of this project, the calibration was performed on one of the towers of the fortification wall. Images are taken in a series of six positions in a pyramid shape and at each position images are taken with the camera in the landscape position, and rotated to portrait in both directions. The change in position and camera orientation allows for the 
distortion at all parts of the lens to be reliably solved. Processing of the camera calibration is done using ADAM Technology's CalibCam. Once the camera and lens are calibrated, the internal settings of the camera are fixed (focus, fstop, and focal length) and remain unchanged for the duration of the calibration sequence, and the subsequent photography. The camera calibration solves for 11 unknown parameters that model the distortion of the lens. The most important value is $\mathrm{C}$, which represents the focal length. While any lens or camera has a stated focal length, it is never perfect (BLM, 2008). In our case, the focal length of the lens was $24 \mathrm{~mm}$, but the $\mathrm{C}$ value was calculated to be $24.651 \mathrm{~mm}$. The other parameters include radial lens distortion (K1, K2, K3), principal point offset (XP, $\mathrm{YP}$ ), decentering/tangential distortion (P1, P2), and pixel scaling factors (B1, B2). Precalibrating the camera also speeds up the alignment of image-sets later on as fewer parameters need to be solved.

The photography used for the photogrammetry of the Theodosian Palace was of two types, depending on whether the photos would be used for ground plan or section drawings. Nadir photography was used to create the ground plan model of the building and the terrestrial for the sections of each unconserved wall. For the nadir photography, a Nikon D800E DSLR camera with a Nikkor $24 \mathrm{~mm}$ prime lens mounted on a carbon fibre pole at a height of $5 \mathrm{~m}$ is used. Prime lenses, that is lenses with a single focal length, are preferred for photogrammetry because they eliminate the possible source of error due to accidentally adjusting the collar of a zoom lens. The carbon fibre pole has a gravity gimbal at the top where the lens is mounted. This gimbal is built such that no matter the angle of the pole, the camera will always hang in a position perpendicular to the ground such that vertical imagery can be reliably acquired. A remote control with wireless capabilities is connected to the camera so that the camera settings and shutter release can be controlled from the ground through the use of a portable tablet. Images were taken in strips along the walls with the camera in a nadir position. The terrestrial photography was performed using the same camera and lens, but mounted on a monopod at a height of 0.5-2 m depending on the height of the wall. Images were again taken in strips moving along the wall at two different heights to ensure full coverage from the ground level to the top of the walls. Table 1 outlines the expected and actual accuracies of the models. The expected accuracy refers to the maximum, a priori accuracy of the photogrammetric data before the limitations of scaling or georeferencing is taken into account. This a priori accuracy is calculated based on the resolution of the camera, focal length of the lens, and the distance from the wall.

\begin{tabular}{|c|c|}
\hline Parameter & Value \\
\hline Camera Model & Nikon D800E \\
\hline Lens & Nikkor FX 24mm \\
\hline Focal Length & $24 \mathrm{~mm}$ \\
\hline Aperture (F-Stop) & F/6.3 \\
\hline Max Resolution & $3360 \times 4912$ \\
\hline Sensor Size & $0.6 \mathrm{~mm}$ \\
\hline Ground Pixel Size & 0.2 pixels \\
\hline Image Accuracy & $<1 \mathrm{~mm}$ \\
\hline $\begin{array}{c}\text { Expected Accuracy } \\
\text { (photogrammetry only) }\end{array}$ & $\sim 3 \mathrm{~mm}$ \\
\hline $\begin{array}{c}\text { Actual Accuracy } \\
\text { (georeferenced) }\end{array}$ & \\
\hline
\end{tabular}

Table 1 - Photogrammetry Camera and Lens Parameters
For both the nadir and terrestrial photogrammetry, a series of Leica-brand HDS circular targets were placed on the walls. They were originally designed for use with Leica LiDAR scanners. In the case of the ground plans, they were placed on top of the wall, and for the sections, they were fitted into the stones of the walls. The Leica TPS1201+ Total Station was mounted on the higher modern pathways surrounding the building and measurements were taken of each target to orient the models within the coordinate system of the site. These targets could be picked-up automatically and with sub-pixel accuracy in the photogrammetry software using a centroiding algorithm.

The ground plan photography was done in four chunks in the field due to the need for multiple total station setups to measure the control points across the building. The multiple chunks also served to reduce the file sizes and make the final models more manageable. For the individual wall sections, each of the 28 unconserved walls was photographed and processed individually to account for the different directions of each wall.

\subsection{Photogrammetric Workflow}

Two software packages were used in this project, Agisoft Photoscan Version 1.3.2 Build 4205 (Agisoft, 2017) and ADAM Technology Mine Mapping Suite (CalibCam and 3DM Analyst) Version 2.5.0 Build 1644 (ADAM Technology, 2017), which both use mathematical algorithms to place points on matching features on the object between two images. Agisoft Photoscan was used for the generation of the 3D models and orthophotos, and 3DM Analyst was used mostly for the drawing process and pre-calibration. The initial matching points between the images and the exterior orientation of the cameras are visualized in the sparse cloud in both software packages. This visualization offers a first check of quality and can help to identify areas that have poor photo-coverage.

It should be noted that we do not add control until after the alignment of the photos. The models are only then georeferenced using the coordinates of the centroiding targets. As predicted, the residuals on the control points averaged $3 \mathrm{~mm}$ in $\mathrm{X}, \mathrm{Y}, \mathrm{Z}$, a value that agreed with the accuracy of our control network. The texture model is most often used as a digital surrogate and provides an interactive experience with the archaeological features that can be rotated and enlarged by the user. Note that Agisoft Photoscan has a strong tendency to "overmatch" and points are generated even for the sky above the wall. This is observable in the "fringe" above all of the wall-sections. Rather than being a problem, however, this actually aided in the delineation of the top of the wall. More conservative matching algorithms like Normalized CrossCorrelation were found to actually cut the top of the wall where camera look-angles were less than ideal.

The four chunks for the ground plan of the building and the individual wall sections were processed separately. Once the models are processed and geo-referenced, they are exported from Agisoft Photoscan as OBJ files and imported into ADAM Technology's 3DM Analyst, a system used in the mining and mapping industries for vectorization and stereoplotting. The models are opened individually and are visualized with 3D glasses in their coordinate system (Fig. 4, 5, 6, \& 7). 


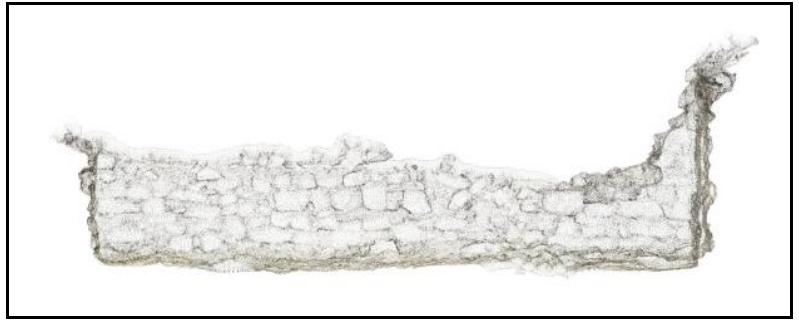

Figure 4. Wall Section Dense Cloud

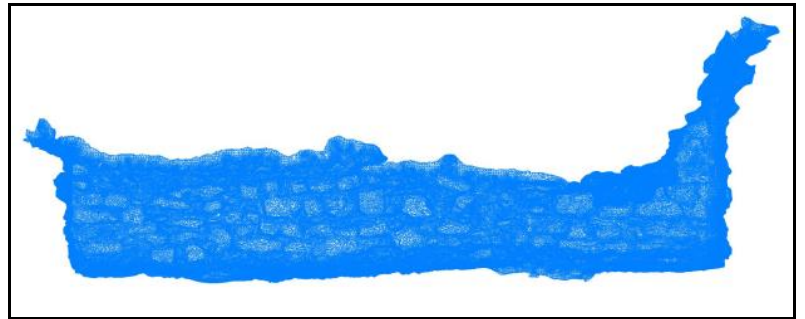

Figure 5. Wall Section Mesh

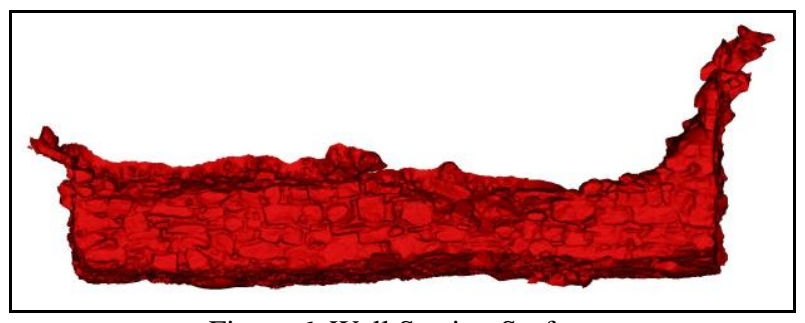

Figure 6. Wall Section Surface

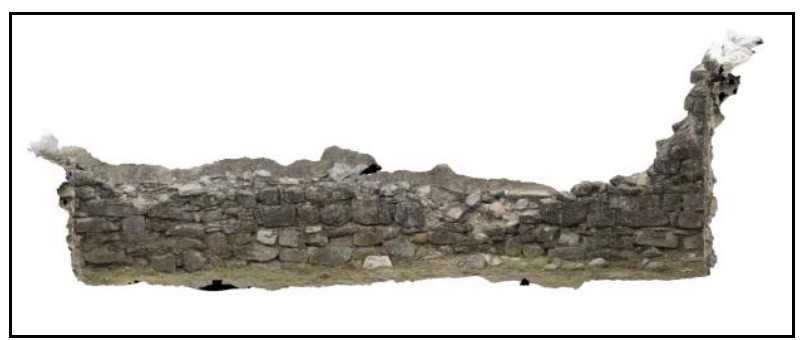

Figure 7. Wall Section Texture

Orthophotos of each of the walls are generated using Agisoft Photoscan because it is ideal for creating visually pleasing true orthophotos. Using the Mosaic blending mode, the pixel information on the surface of the 3D model from the individual high resolution photos are stitched together and the seams between the images blended to eliminate the borders of the individual photos to create a single high resolution image of the entire surface of the model. True orthophotos eliminate the effect of relief displacement in the individual images. Along with the high resolution orthophoto (JPG or TIFF), a World File is generated that contains the georeferencing information of the model so the image can be imported into AutoCAD Map 3D or other GIS software in its position within the coordinate system of the site. The orthophotos are also used as a reference once the drawings are completed and for visual documentation of the state of the individual walls instead of using multiple single images.

\subsection{From Stereoplotting to Final Records}

The initial drawings are done in ADAM Technology's 3DM Analyst. The software provides the ability to very accurately vectorize small features while viewing the model in $3 \mathrm{D}$ using anamorphic or LCD active shutter glasses. This allows the operators to recover the same intuitions about the wall as if they physically were present on site. The texture from the high resolution photographs aids in defining variations in flat features such as cracks in stone. Drawing at a scale of 1:1 directly onto the 3D surface of the model in the coordinate system of the site provides a very accurate base for the creation of these drawings (Fig. 8). Features of the model are defined using a Feature Definition File and are separated into layers according to their attributes for further processing. It is important to separate the features into separate layers during the original drawing process so they retain the information when transferred to 2D line drawings. The majority of the features on these walls are stone with a few bricks and marble spolia.

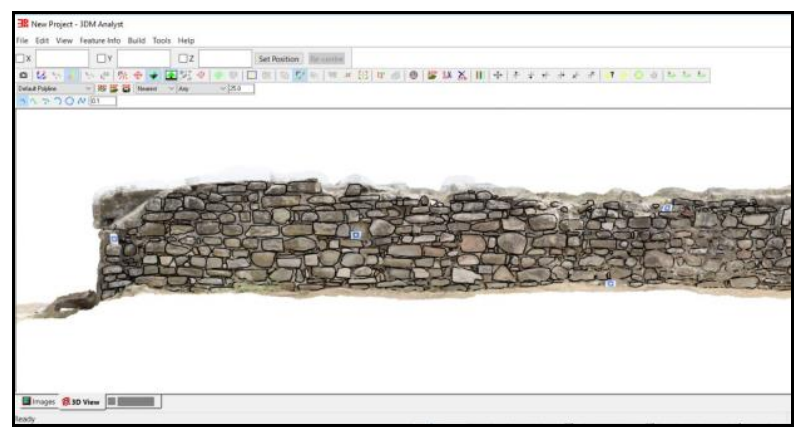

Figure 8. Completed Drawing of Wall Section in 3DM Analyst

Once the features are drawn in 3DM Analyst, they are exported as a DXF file and imported into AutoCAD Map 3D (Autodesk, 2016) for further processing and the finalization of the drawings. In order to transform the drawing done on the $3 \mathrm{D}$ model into the required two-dimensional line drawings, the drawings must be rectified to a two-dimensional X-Y plane. The rectification process in AutoCAD is different for drawings of the ground plan and the individual sections. The ground plan drawings are simply imported, the height or $\mathrm{Z}$ component removed, and then edited directly. Contour lines are added to outline the walls and display any breaks for doorways and staircases. In the case of the Theodosian Palace, only the walls that have not yet been conserved were drawn stone-by-stone. The previously conserved areas only received contour lines outlining the extent of the walls. The ground plan requires the following information for the official archaeological record: multiple vertical levels along the top of the walls; labels for the rooms and wall numbers attributed to the building; and scale bar and North arrow (Fig. 10).

The section drawings presented a greater challenge, as they were drawn in $3 \mathrm{D}$ and must be rectified in respect to $2 \mathrm{D}$ the plane that defines the trend of the wall. This process is done through two steps. First, the rotation angle in the trend-plane must be determined. Using the original $3 \mathrm{D}$ model, a plane is fitted by least squares to five to 20 points selected along its extent. This plane then provides the dip (vertical angle) and dip-direction (horizontal angle) of the wall. The plane's dip direction will then provide the rotation angle for the rectification (Fig. 9). 


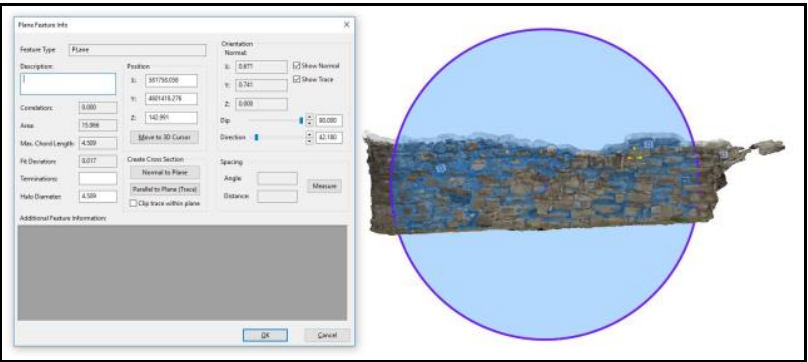

Figure 9. Section Plane Angle Calculation in 3DM Analyst

Once that angle is determined, the drawing is rotated in AutoCAD by that angle so it lies directly on the X-axis. Next, the drawing is rotated -90 degrees in the $\mathrm{Z}$ plane as if it were an aerial project. Unfortunately, georeferencing is lost in this transformation of the drawing into this new X-Y plane, as is all depth information. The scale of the drawing, on the other hand, is perfectly retained at a scale of 1:1. All of the individual wall sections are imported into a single file to be retained as record and referred to for future small-scale maintenance work. In addition to the information included in the top plan drawings, the section drawings also require the following: multiple vertical levels along the top and bottom of the walls; a scale bar at the side of the wall showing elevation values; a scale bar at the bottom of the wall indicating length and any breaks; hatching for the ground level and mortar between the stones; and a legend for the hatching (Fig 10).

In addition to the individual wall sections, a total of five cross sections were also made of the building (Fig. 11). Cross sections are traditionally done by manually measuring the distances over bisecting walls and arbitrarily connecting the drawings. Our digital method, on the other hand, consists of drawing the entirety of the targeted walls in $3 \mathrm{D}$ so the exported vector data is already aligned and only require the addition of the wall outlines and labels differentiating each room and wall number. All of the section and ground plan drawings are processed to the requirements of archaeological technical drawings in the Republic of North Macedonia which must be printed at the scale of 1:50 for the permanent record. Scale is only applied to the drawings during the plotting process; the original digital files retain their scaling of $1: 1$.

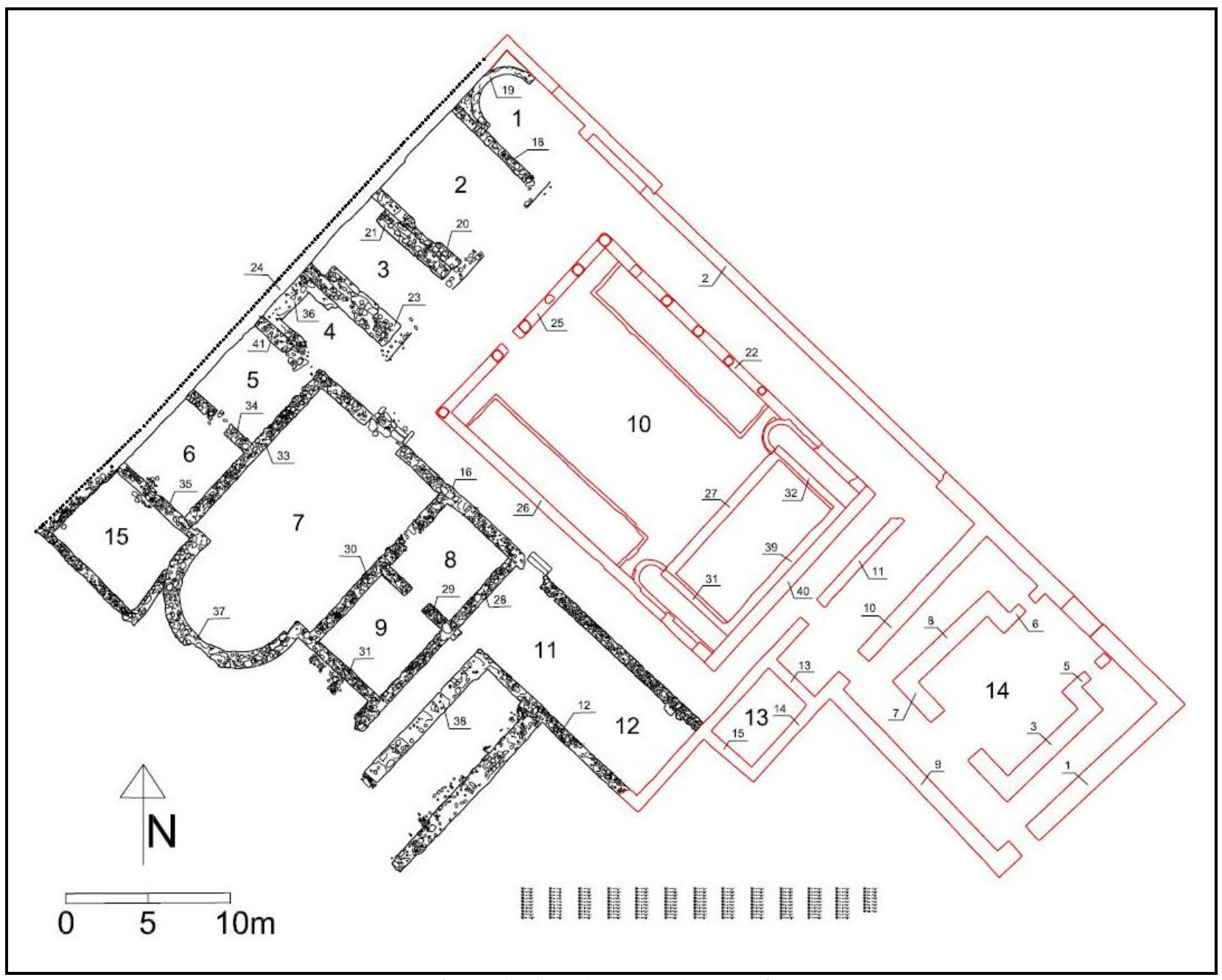

Figure 10. Complete Top Plan Drawing 


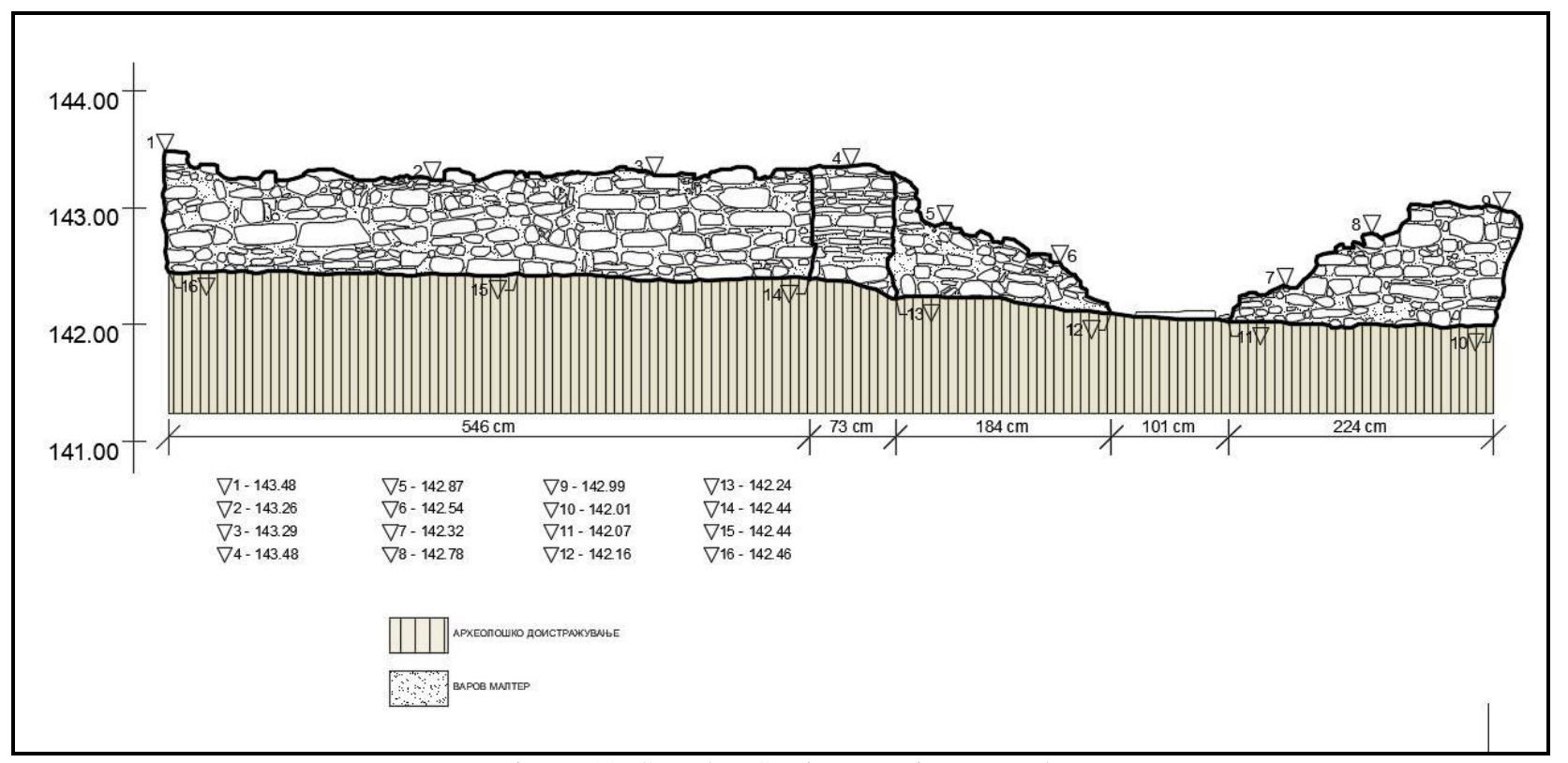

Figure. 11. Complete Section Drawing Example

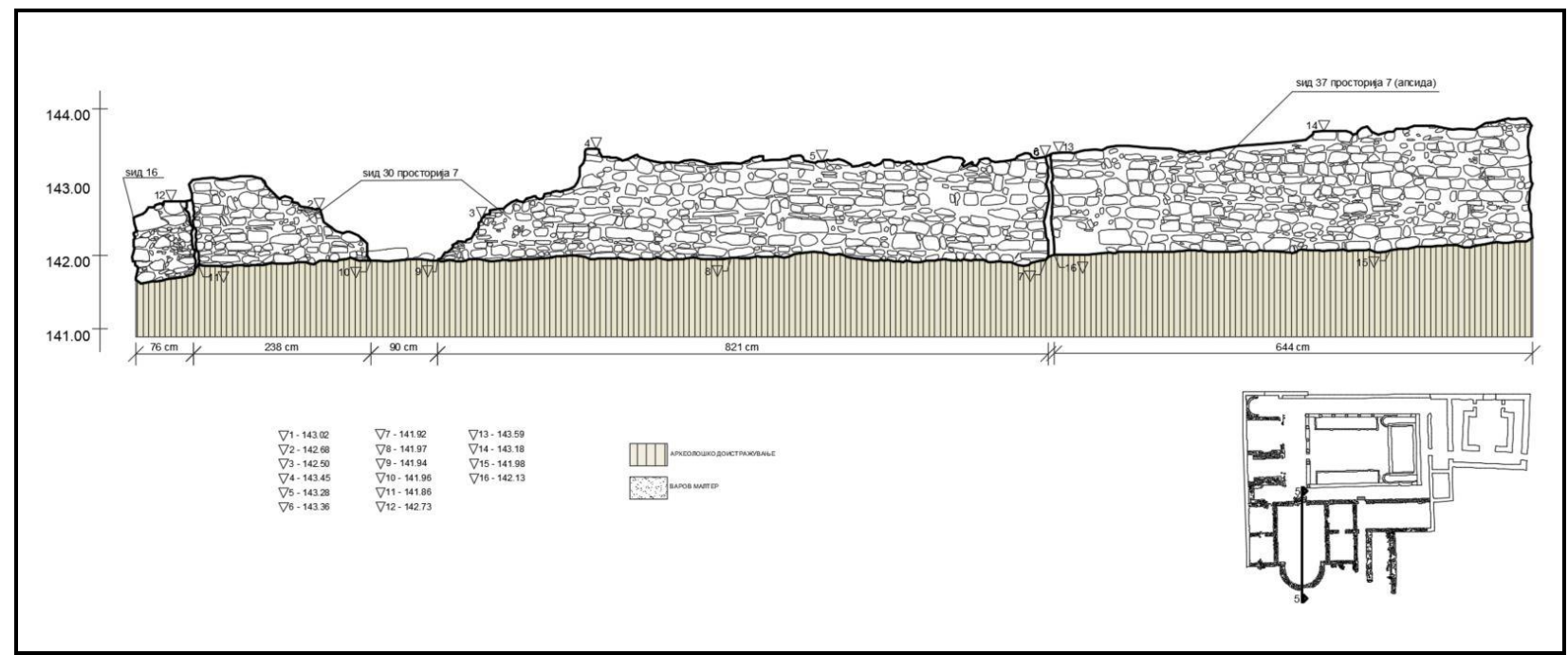

Figure 12. Completed Cross Section Example

\section{RESULTS \& CONCLUSIONS}

This project concluded with the production of a complete set of drawings for each unconserved wall in the Theodosian Palace at Stobi. This inventory, along with the written wall narratives, mortar samples, and proposal, is the basis for the conservation project. A total of 28 wall sections were documented, totalling approximately $250 \mathrm{~m}$ in length, along with five cross-sections of the building, and the ground plan. Photogrammetry provides a highly accurate and solution to mass stone-by-stone recording that is a significantly faster alternative to manual drawing.

The process of using photogrammetric data for 2D drawings of ground plans and other features modelled from nadir imagery is well established. The drawing of sections and facades, on the other hand, remains a problem that has yet to be solved elegantly in a single step. Our method of rotating the section drawings using the rotation angle provided by the $3 \mathrm{D}$ model was successful for this project, but further investigation of alternative methods is required. During the 2018 season at Stobi, we developed a method for rectifying wall sections using an L-shaped target made up of two scale bars mounted next to the wall. The two target bars are attached at a $90^{\circ}$ angle and levelled parallel to the wall with the use of a small, sturdy tripod and a flexible arm and clamp system (Fig. 13). With the L-target aligned in this way, we are able to rectify the wall in a local coordinate system in the photogrammetric software and set the two scale bars to represent the $\mathrm{X}$ and $\mathrm{Y}$ axes as if the wall was being photographed as an nadir project. The coded targets on the individual scale bars have known distances that provide accurate te scaling for the models and replace timeconsuming ground-control points measured with the total station. In addition to the L-target, two additional scale bars are placed along the wall to ensure accurate and redundant scaling across the entirety of the model area. This process removes sources of error related to the rotation method and streamlines the drawing process. The limitation of this method, however, is that the walls do not have any georeferencing information and are all in an arbitrary local coordinate system. Generally this is not a problem because the georeferencing information is not necessary for the drawing of wall sections. The obvious 
disadvantage of this method, however, is that it does not allow the creation of cross-sections, which needs absolute orientation for several walls. Cross-sections, however, could still be obtained using the L-target if the targets on the scale bars were also measured with the total station. This combination would provide the ability to both obtain a scaled model automatically transformed into 2D X-Y coordinates for individual section drawing, and have the georeferencing information available for determining the absolute spatial relationship to other walls for cross-sections, if this is needed.

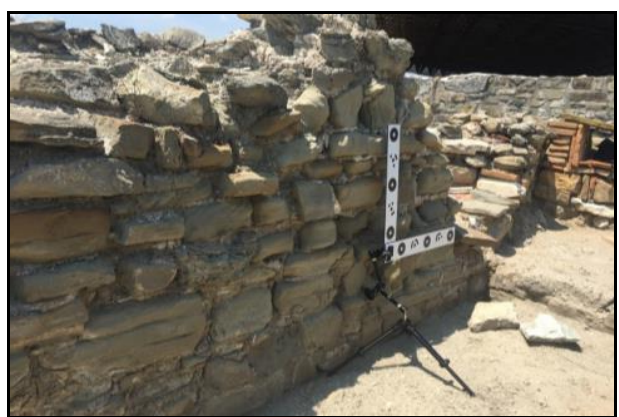

Figure 13. Set-Up for L-Target Photography

The application of historical stereoplotting methods that have been in use for over a century provided the optimal solution for the mass recording of archaeological structures. The project for the documentation of the Theodosian Palace at Stobi concluded with the near-complete preparation for the project for the conservation of the Theodosian Palace to a higher accuracy and in less time than would have been otherwise possible. The use of $3 \mathrm{D}$ glasses in the drawing process also means that an operator in Canada, for instance, can have the same intuitions about where to draw lines as would an architect on site at Stobi with no reduction in accuracy. It is important to note that simply using the orthophotos for drawing directly in AutoCAD in 2D can also be done in many cases with little loss in accuracy. Often 3D viewing of the models is used as a later quality-control check, especially when ambiguities or uncertainties arise in the drawing of contours. This project determined that a combination of the two processes is the optimal solution.

To conclude, it is clear from this project that the implementation of photogrammetric documentation techniques is important for archaeological recording. Since the invention of terrestrial photogrammetry by Meydenbauer in the late 19th century, the cost and expertise required for photogrammetry and stereoplotting has gone down substantially and opens the door for mass implementation in archaeology, a traditionally low-resource profession. While photogrammetry is quickly becoming a standard technique in cultural to produce photorealistic 3D models, there is still a great need for more work, principally in software development, to simplify the process of extracting 2D drawings from these 3D models. These 2D drawings are still a useful level of abstraction and will not be easily replaced by 3D models in the near future in many jurisdictions.

\section{ACKNOWLEDGEMENTS}

Special thanks to the staff of National Institution Stobi for allowed our research to be conducted at the site since 2015 . Without the endorsement of National Institution Stobi, this project would not have been possible.

\section{REFERENCES}

ADAM Technology. (2017) ADAM Technology Mine Mapping Suite Software, Version 2.5.0 Build 1644. http://www.adamtech.com.au (14 June 2017).

BLM (Bureau of Land Management). (2008). Aerial and CloseRange Photogrammetric Technology: Providing Resourse Documentation, Interpretation, and Preservation. BLM Technical Note vol. 428.

Agisoft. (2017). Agisoft Photoscan Sofware, Version 1.3.2 Build 4205. https://www.agisoft.com (20 May 2017).

Autodesk. (2016). Autodesk AutoCAD Map 3D 2016 Software. https://www.autodesk.com/.

Hemens, F.P. (1986). Late Antique Residence at Stobi, Yugoslavia (PhD Dissertation). Boston: Boston University.

Heuzey, L. (1973). Découverte des Ruines de Stobi. Revue Archéologique, Nouvelle Série vol. 2, 25-42.

Leica Geosystems. (2007). Leica TPS1200 Technical Reference Manual. Heerbrugg: Leica Geosystems.

Mikulcic, Ivan. (1981). Some New Factors in the History of Stobi. In Blaga Aleksova \& James Wiseman (Ed.) Studies in the Antiquities of Stobi III (pp. 215-228). Titov Veles: Macedonian Review Editions.

MicroSurvey. (2014). MicroSurvey Star*Net Software, Version 8. http://www.microsurvey.com. (9 May 2014).

Petkovic, W.R. (1928). Report of 1927-28 [Stobi Excavations]. Godisnjak Srpska Akademija Nauka vol. 37, 188-192.

Petkovic, W.R. (1929). Report of 1929 [Stobi Excavations]. Godisnjak Srpska Akademija Nauka vol. 38, 231-234.

Snively, C. (2010). Macedonia in Late Antiquity. In Joseph Roisman \& Ian Worthington (Ed.) Companion to Ancient Macedonia (pp. 545-571). Oxford: Wiley-Blackwell Publishing.

Wiseman, J. (2007). Environmental Deterioration and Human Agency in Ancient Macedonia: A Case Study. Geoarchaeology vol. 22.1, 85-110.

Waldhäusl, P. \& Ogleby, C. (1994). 3x3 Rules for Simple Photogrammetric Documentation of Architecture. International Archives of Photogrammetry and Remote Sensing. XXX-5, 426-429.

von Hahn, J.G. (1961). Reise von Belgrad nach Salonik. K. Akademie der Wissenschaften, Vienna. PhilosophischeHistorische Klasse. Denkschriften vol. 11.2, 231-236. 